\title{
Forensic Study of Child Abuse in Bangladesh
}

\author{
Md Syedur Rahaman Sumon ${ }^{1 *}$, Zamilur Rahman ${ }^{2}$, Md Belayet Hossain Khan $^{3}$, Sohel Mahmud ${ }^{4}$ \\ ${ }^{1}$ Associate Professor, Department of Forensic Medicine and Toxicology, Bashundhara Ad-din Medical College, Dhaka, Bangladesh \\ ${ }^{2}$ Assistant Professor, Department of Anatomy, Monno Medical College, Manikgonj, Bangladesh \\ ${ }^{3}$ Professor, Department of Forensic Medicine and Toxicology, Sir Salimullah Medical College Medical College, Dhaka, Bangladesh \\ ${ }^{4}$ Associate Professor \& Head, Department of Forensic Medicine and Toxicology, Dhaka Medical College, Dhaka, Bangladesh
}

\begin{abstract}
Introduction:The future reflection of nation child has some common problem like under-nutrition, infections, as well as abuse or maltreatment is equally important. World Health Organization (WHO) reported that worldwide, approximately $20 \%$ of women and $5-10 \%$ of men report being sexually abused in childhood? In Bangladesh, a large number of children are exposed to severe forms of sexual, physical and mental abuses at home, in the work place, in institutions and other public places.

Methods and Results: A total of 96 children below 18 years above 5 years were included in this research. All the statements made by semi structured interviews and physical examination. About $6 \%$ child reported they are referred as idiot and called them foul name being considering them emotionally abused child. $34 \%$ child considering physically abused (by burn $34 \%$ and by beating $55 \%$ ). $60 \%$ child considering sexually abused. Among them depending on the type of sexual abuse $12 \%$ reported someone trying to touch or kissing or even touched their private body parts, $27 \%$ reported someone trying to show naked or dirty pictures to them by using mobile, $61 \%$ reported that someone put or forced his private organ inside their mouth (11\%), anus $(32 \%)$ or vagina $(57 \%)$.

Conclusion: Child abuse is a global problem. Not in the world but also in Bangladesh. So Bangladesh government should give special attention to safety of child. To prevent child abuse in social life like children on the street, children at work, and children in institutional is a punishable act as per the Protection of Children from Sexual Offenses Act in our parliament.
\end{abstract}

Keyword: Child abuse, Rape, Sexual offence.

Int J Eth Trauma Victimology (2020). DOI: 10.18099/ijetv.v6i02.5

\section{INTRODUCTION}

$\mathrm{C}$ Thildren are the assets to every society and regarded as the future architect of a nation. In Bangladesh male and female children are abused sexually and physically. According to Mason and Purdue children are exposed to different forms of violence that impedes their mental, physical, psychological and moral growth. ${ }^{1}$ About half of the populations of Bangladesh are under the age of 18 who are considered as children and more than 20 million of them are under the age of 5. Children of poor socio economic status, unemployed parents, young single parents and children having parental conflicts are usually at risk of being the victims of abuse and neglect. United Nations Children's Fund (UNICEF) reported that the percentage of girls marrying before 18 years was 65 and $29 \%$ girls marry by the age of 15 years. $^{2}$ Corporal punishment is unlawful in schools of Bangladesh according to a Supreme Court judgment issued on 13 January 2011. ${ }^{3}$ There is little singular law that looks at children in every vulnerable situation. Now a days, it has been estimated that the total number of domestic child workers in the country vary from $2,00,000$ to a million. UNICEF reported that about $25 \%$ of housewives report that they physically beat child domestics to punish them for poor performance or ill behavior. ${ }^{4}$ It is also challenging Child trafficking in Bangladesh. According to Akter, criminal networks engage these children in commercial sex work, smuggling, stealing and distribution of drugs and weapons. ${ }^{5}$ Violence against children is causing increasing concern in
Corresponding Author: Dr. Md Syedur Rahaman Sumon, Associate Professor, Department of Forensic Medicine \& Toxicology, Bashundhara Ad-din Medical College, e-mail: drsumonadib@gmail.com

How to cite this article: Sumon MSR, Rahman Z, Khan MBH, Mahmud S. Forensic Study of Child Abuse in Bangladesh. Int $J$ Eth Trauma Victimology 2020;6(2):19-21.

Source of support: Nil

Conflict of interest: None declared

Received: 11/10/2020; $\quad$ Received in revised form: 08/11/2020;

Accepted:29/11/2020;

Published:25/12/2020

Bangladesh and work as a vicious cycle where the abused or neglected children will eventually victimize their own children that altered brain maturation have long-term consequences for cognitive, language and academic abilities. Despite this, schools punishment is widespread in most of the schools. In reality different laws to protect the children from abuse and to ensure their rights but in practice these remained failure. Government should identify the scale of the problem and create stronger laws to protect the rights of our children by creating public awareness about child education and risky child labor, strengthening family ties, early reporting of child abuse.

\section{Materials and Methods}

The present study was descriptive cross sectional type. The research was carried out in the Department of Forensic Medicine, 
Sir Salimullah Medical College (SSMC), Dhaka during the period of January to June 2015 after approval from the Ethical Committee of Institutional Review Board (IRB), SSMC to measure the scenario of child abuse in Bangladesh. By searching documents, semi structured questionnaire was formulated in Bangla as well as in English also. After being informed about the study, participants were asked sign a written informed consent form that explained the nature and purpose of the study, as well as its likely risks and benefits. Afterward, the researcher asked questionnaire face-to-face of the victim in comfortable or preferred language (Bangla). Age of the recruited victims was equal or above 5 but below 18 years.

\section{RESULT}

A total of 96 victims were included in the research out of which 72 were female children and 24 were male children. The informations are shown in Tables 1 and 2.

Among these 96 victims, about $6 \%$ child reported they are referred as idiot and called them foul name being considering them emotionally abused child. A total of $34 \%$ child considering physically abused (by burn $34 \%$ and by beating $55 \%$ ). $60 \%$ child considering sexually abused. Among them depending on the type of sexual abuse $12 \%$ reported someone trying to touch or kissing or even touched their private body parts, $27 \%$ reported someone trying to show naked or dirty pictures to them by using mobile, $61 \%$ reported that someone put or forced his private organ inside their mouth (11\%), anus $(32 \%)$ or vagina $(57 \%)$. The research found mental, physical and sexual abuse of child are shown in Figure 1.

\section{Discussion}

Child abuse is a silent epidemic. ${ }^{6}$ Child abuse can take several forms like physical abuse, psychological abuse, neglect and sexual abuse. According to the study 5-9 years children are

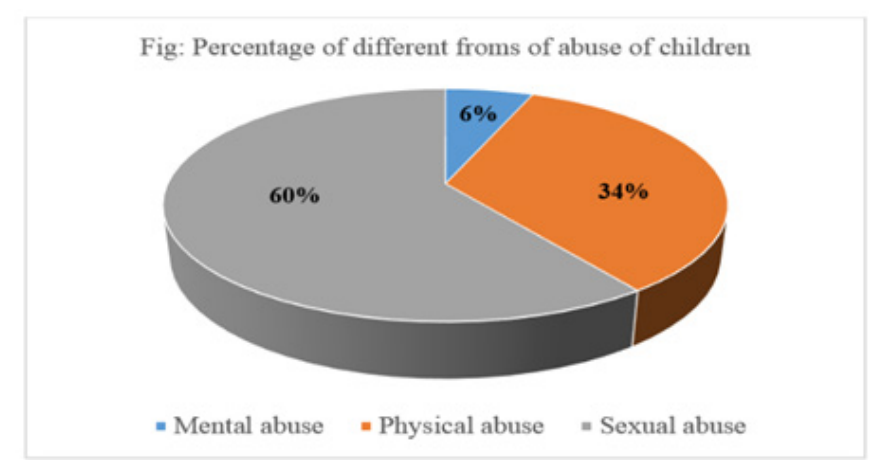

Figure 1: Percentage of different forms of child abuse

Table 1: Age and sex distribution of abused child in Bangladesh:

\begin{tabular}{lll}
\hline & \multicolumn{2}{l}{ Sex of victims } \\
\cline { 2 - 3 } Age in year & Male & Female \\
\hline $5-9$ & 14 & 36 \\
$10-14$ & 7 & 28 \\
$15-<18$ & 3 & 8 \\
Total number of victims & 96 & \\
\hline
\end{tabular}

more vulnerable to child abuse. In present research, mental abuse $6 \%$, physical abuse $34 \%$ and sexual abuse $60 \%$ were found. Under physical abuse, the research found 34\% burn, $55 \%$ victims were affected by beating. Others found starvation, closed /door locking. Among sexual abuse 12\% found some touch private part or kiss them. About $27 \%$ of sexually abused child complain that some enforced them to see dirty picture by non-contact activities. Most of the sexually victims child suffered someone forced his private organ inside his or her anus or vagina. Female children are more vulnerable for child abuse. Some studies have reported that female victims of Child abuse are three to five times more likely to suffer further sexual assault than those who have not suffered child abuse., In our study, 33(35\%) victims were abused by neighbor, while $26(27 \%)$ victims were by relatives. Bangladesh is a densely populated country with populations about 160 millions. Most of the children of Bangladesh are deprived from basic rights like education, balance diet, health and nutrition, protection, participation, recreation, safe water, sanitation and abused sexually and physically. Street children and child always falls victim of verbal, physical, and sexual abuse from police, gangster and the general public. In the United States, the Centers for Disease Control and Prevention (CDC) and the Department for Children and Families (DCF) define "child maltreatment as any act or series of acts of commission or omission by a parent or other caregiver that results in harm, potential for harm, or threat of harm to a child. ${ }^{9}$ Based on above definition, the present research found three major types of maltreatment against children. In Bangladesh, there exist different laws to protect the children from abuse and to ensure their rights but in practice these remained uncontrolled. Emotional abuse includes the failure of a caregiver to provide an appropriate and supportive environment about 6 children. So, this study found various of different type of elements use in child abuse. Although illegal, child marriage remains a widespread practice in Bangladesh before the age of 15 years. The present studies found about 50 children below 10 years were victimized more. Government alone can't solve this problem alone. So differences in these cultural beliefs demonstrate the importance of examining the legal and cultural perspectives while studying the concept of child abuse..$^{10}$ As in most studies that focus on the sexuality of children, adolescents, and young people, we must demand more and better education in this area, from an early age and without taboos. ${ }^{11}$ The early experience of child abuse can trigger changes in child's behavior including discipline problems, insomnia, nightmares, anxiety, and depression Table 2: Child abuse victims according to the relationship to accused

\begin{tabular}{lll}
\hline Relationship to accused & Frequency & Percentage \\
\hline Neighbor & 33 & 35 \\
Relatives & 26 & 27 \\
Stranger & 15 & 15 \\
Teacher & 9 & 9 \\
Friends & 13 & 14 \\
Total & 96 & 100 \\
\hline
\end{tabular}


etc. This also causes problem with mental development of a child which interrupt his feelings, empathy, sympathy, reasoning, rational thinking and benevolence. Children who have been abused or neglected are more likely to be arrested as juvenile offenders and are more likely to be a sadist and involve in criminal activities as an adult. ${ }^{1}$ There is a range of laws in Bangladesh designed to protect children, but they apply varyingly to children indifferent situations. There is no singular law that looks at children in every vulnerable situation they may find themselves in. Government should recognize the scale of the problem and create stronger laws to protect the rights of our children by creating public awareness about child education and risky child labor, strengthening family ties, early reporting of child abuse cases to the law enforcement authority, developing and sustaining prevention programs and facilitating.

\section{Conclusion}

At last we can conclude that child abuse is a global problem. Female child are the most vulnerable to sexual violence, but recently male children are also sexually harassed. It is difficult to document intra familiar sexual abuse and manage, because the child must be protected from additional abuse and coercion not to reveal or to deny the abuse, while attempts are made to preserve the family unit. This study documented the childhood prevalence of emotional, physical and sexual abuse is increasing in town life. It is also noteworthy that school teachers were responsible for physical abuse recently considering it an important maltreatment for child. Situation demands that this issue of addressing child abuse should be given importance and their preventive efforts should be given to strengthen care giver/parent-child interaction by ensuring strict implementation of law.

\section{REFERENCES}

1. Mason J, Purdue B. The physically and emotionally abused child. In: The pathology of trauma. 3rd ed. New York: Oxford University press; 2000.

2. Ending Child Marriage: Progress and prospects [Internet]. UNICEF DATA. 2014 [cited 2020 Dec 12]. Available from: https://data.unicef.org/resources/ending-child-marriageprogress-and-prospects/

3. Mohiuddin H, Khatun A, Al-Kamal M. Corporal Punishment in Bangladesh School System: An Analytical Appraisal of Elimination Strategy Directions. ASA Univ Rev. 2012;6(2).

4. Daily lives of working children. Dhaka. UNICEF; 1997.

5. Aktar J. Health and living conditions of street children in Dhaka City. Dhaka Bangladesh ICDDRB. 2004;

6. Islam F, Akhter GA. Child abuse in Bangladesh. Ibrahim Med Coll J. 2015;9(1):18-21.

7. Pereda N, Abad J, Guilera G. Lifetime prevalence and characteristics of child sexual victimization in a community sample of Spanish adolescents. J Child Sex Abuse. 2016;25(2): $142-158$.

8. Godbout N, Vaillancourt-Morel M-P, Bigras N, Briere J, Hebert $\mathrm{M}$, Runtz $\mathrm{M}$, et al. Intimate partner violence in male survivors of child maltreatment: A meta-analysis. Trauma Violence Abuse. 2019;20(1):99-113.

9. Bromfield L. Chronic child maltreatment in an Australian statutory child protection sample. Deakin University; 2005.

10. Akter K. Unseen wounds of abused children. The Daily Star. 2015 Aug 4;

11. Castro Á. Sexual behavior and sexual risks among Spanish university students: a descriptive study of gender and sexual orientation. Sex Res Soc Policy. 2016;13(1):84-94. 